\title{
PENERAPAN CONTEXTUAL TEACHING AND LEARNING PADA PEMBELAJARAN SENI RUPA MATERI MENGGAMBAR BENTUK
}

\author{
Aung Sayadi \\ SMPN 2 Palimanan Cirebon, Indonesia \\ aungsayadi@gmail.com
}

\begin{abstract}
In the implementation of fine arts learning many class students have not mastered the ability to draw shapes. The author makes an effort to improve students' ability to draw shapes using Contextual Teaching and Learning Techniques. The method used in this research is Classroom Action Research with the subjects of VII grade students of SMP Negeri 2 Palimanan as many as 36 students. The purpose of this study was to improve the ability of VII grade students of SMP Negeri 2 Palimanan in drawing shapes on Fine Arts subjects using Contextual Teaching and Learning techniques. The study was conducted in two cycles, with the results of the use of Contextual Teaching and Learning techniques in learning to draw shapes can improve the learning achievement of Grade VII students of SMP Negeri 2 Palimanan on the form drawing material.
\end{abstract}

Keywords: contextual teaching and learning, fine arts, learning achievement.

\section{ABSTRAK}

Dalam pelaksanaan pembelajaran seni rupa banyak siswa kelas yang belum menguasai kemampuan menggambar bentuk. Penulis melakukan upaya meningkatkan kemampuan siswa dalam menggambar bentuk dengan menggunakan Teknik Contextual Teaching and Learning. Metode yang digunakan dalam penelitian ini adalah Penelitian Tindakan kelas dengan subjek penelitian siswa kelas VII SMP Negeri 2 Palimanan sebanyak 36 siswa. Tujuan Penelitian ini adalah untuk meningkatkan kemampuan siswa kelas VII SMP Negeri 2 Palimanan dalam menggambar bentuk pada mata pelajaran Seni Rupa dengan menggunakan teknik Contextual Teaching and Learning. Penelitian dilaksanakan sebanyak dua siklus, dengan hasil Penggunaan teknik Contextual Teaching and Learning dalam pembelajaran menggambar bentuk dapat meningkatkan prestasi belajar siswa kelas VII SMP Negeri 2 Palimanan pada materi menggambar bentuk.

Kata Kunci: contextual teaching and learning, seni rupa, prestasi belajar.

Submitted Feb 25, 2020 | Revised Mar 22, 2020 | Accepted Mar 24, 2020

\section{Pendahuluan}

Belajar merupakan proses kreatif dari seseorang untuk meningkatkan kemampuan dirinya menjadi lebih baik, lebih berguna tanpa ada batasan ruang, waktu, media, tempat maupun dimensi yang ada. Didalam belajar, tidak hanya pada satu tempat saja akan tetapi di mana pun dan kapan pun belajar dapat dilakukan. Siapa saja dapat belajar sesuai apa yang disenangi dan dapat dilakukannya. Belajar tidak mengenal usia, jenis kelamin, status ekonomi, sosial, maupun kepercayaan karena belajar bersifat universal dan vasirasi dalam belajar baik tempat belajar, media yang digunakan dalam belajar, metode yang dipakai untuk belajar maupun strategi yang digunakan secara tidak langsung akan membangkitkan motivasi seseorang dalam menggapai ilmu. Menurut Slameto (1995) belajar ialah suatu proses usaha 
yang dilakukan seseorang untuk memperoleh suatu perubahan tingkah laku yang baru secara keseluruhan, sebagai hasil pengalamannya sendiri dalam interaksi dengan lingkungannya. Belajar juga memegang peranan penting dalam perkembangan, kebiasaan, sikap, keyakinan, tujuan, kepribadian, dan bahkan persepsi manusia. Djamarah (2008) menambahkan bahwa belajar adalah serangkaian kegiatan jiwa raga untuk memperoleh suatu perubahan tingkah laku sebagai hasil dari pengalaman individu dalam interaksi dengan lingkungannya yang menyangkut kognitif, afektif dan psikomotorik.

Pembelajaran seni adalah pembelajaran yang menekankan pada beberapa aspek yaitu kognitif, afektif dan psikomotorik (Rofian, 2016). Untuk dapat melakukan pekerjaan-pekerjaan seni rupa, musik, tari, teater dan sastra, diperlukan kompetensi yang mencakup aspek-aspek kognitif, psikomotor dan afektif (Hartono, 2007). Adapun Aspek yang lebih diutamakan dalam pembelajaran seni adalah aspek psikomotorik karena perkembangan kemampuan individu melalui keterampilan diri sangat diutamakan dalam belajar berkesenian. Hal itu, juga tercermin dalam pembelajaran seni rupa karena merupakan salah satu cara untuk mengembangkan keterampilan diri anak serta meningkatkan otak kanan dalam berkreativitas, mengembangkan ide atau gagasan, imajinasi maupun keterampilan dalam memvisualisasikan gagasan atau ide dalam wujud yang nyata.

Pentingnya pembelajaran seni rupa dalam dunia pendidikan merupakan salah satu sarana dan media yang bisa digunakan untuk mengembangkan keterampilan anak serta mengenali dan melatih psikomotorik anak agar lebih baik serta dapat mengembangkan bakat yang sudah dimiliki sebagai sumber kemampuan individu yang perlu diolah dan dilatih secara terusmenerus.

Materi pelajaran seni rupa di sekolah menengah di antaranya adalah menggambar, melukis, mamahat, mematung, grafis, mencetak, dan lain-lain. Banyaknya pilihan dan jenis materi yang terdapat dalam pelajaran seni rupa, maka memungkinkan guru seni rupa dapat memilih materi pelajaran seni rupa yang disesuaikan dengan kemampuan siswanya. Salah satu materi pelajaran seni rupa yang menjadi dasar siswa dalam mengenal pelajaran menggambar adalah dengan memahami dan mempelajari bentuk-bentuk dasar yang ada di lingkungan sekitar. Materi pelajaran yang dimaksud adalah menggambar bentuk. Menggambar bentuk merupakan salah materi pelajaran yang mengutamakan kecermatan dan ketelitian dalam mengamati model, kemahiran tangan dalam menggambar benda nyata ke dalam bentuk karya dua dimensi sesuai dengan wujud asli bendanya. Menggambar bentuk mengutamakan ketepatan bentuk yang digambar karena pembelajaran yang dilakukan bersifat praktikal, sehingga diharapkan siswa dapat meningkatkan kemampuan dirinya agar dapat menggambar bentuk dengan baik.

Secara umum materi pelajaran menggambar bentuk diterapkan di Sekolah Menengah Pertama atau SMP disesuaikan dengan tingkat kematangan belajar siswa. Siswa SMP merupakan masa berkelompok usia 9-13 tahun dan masa realisme semu usia 13-14 tahun. Pada masa berkelompok, gambar yang dihasilkan oleh anak sudah menghasilkan gambar yang berwujud dan dapat dikenali. Anak sudah bisa membandingkan karyanya dengan objek yang dilihat serta menghubungkan bentuk-bentuk yang dibuatnya dikaitkan dengan dunia sekitarnya.

Dalam pelaksanaan pembelajaran menggambar bentuk banyak para siswa kelas VIIB SMP Negeri 2 Palimanan tahun pelajaran 2019/2020 yang belum menguasai kemampuan 
tersebut. Rendahnya kemampuan siswa kelas VIIB SMP Negeri 2 Palimanan dalam menggambar bentuk dibuktikan dengan pencapaian rata-rata nilai tes akhir setelah para siswa mengikuti pembelajaran tersebut yang masih belum mencapai nilai Kriteria Ketuntasan Minimal (KKM).

Menyikapi permasalahan tersebut, penulis sebagai guru mata pelajaran Seni Rupa berusaha untuk memperbaiki pelaksanaan pembelajaran di antaranya dengan menggunakan teknik pembelajaran dan media pembelajaran yang relevan dengan materi pembelajaran tersebut. Dewasa ini banyak teknik pembelajaran yang dapat digunakan dalam pembelajaran menggambar bentuk. Salah satu teknik pembelajaran menggambar bentuk adalah teknik Contextual Teaching and Learning (CTL). Penelitian yang dilakukan Efniati (2019) menunjukkan model pembelajaran ini dapat meningkatkan hasil belajar siswa dalam pembelajaran Seni Budaya.

Menurut Nurhadi (2002) bahwa CTL merupakan konsep belajar yang membantu guru mengaitkan antara materi yang diajarkan dengan situasi dunia nyata siswa, dan mendorong siswa membuat hubungan antara pengetahuan yang dimilikinya dengan penerapan dalam kehidupan mereka sebagai anggota keluarga dan masyarakat. Menurut Sanjaya (2010), CTL adalah suatu strategi pembelajaran yang menekankan kepada proses keterlibatan siswa secara penuh untuk dapat menemukan materi yang dipelajari dan menghubungkannya dengan situasi kehidupan nyata sehingga mendorong siswa untuk dapat menerapkan dalam kehidupan mereka. Menurut Jhonson (2007) pembelajaran dan pengajaran kontektual (Contextual Teaching and Learning) sebuah sistem mengajar yang didasarkan pada pikiran, bahwa makna muncul dari hubungan antara isi dan konteksnya.

Dalam pembelajaran kontekstual, siswa akan mengalami proses berpikir yang melibatkan pengalaman yang dekat dengan kehidupan mereka, diharapkan melalui proses berpikir ini dapat meningkatkan kemampuan pemecahan masalah siswa (Amir, 2015). Hakikat pembelajaran CTL adalah konsep belajar yang membantu guru mengaitkan antara materi yang diajarkan dengan situasi dunia nyata siswa dan mendorong siswa membuat hubungan antara pengetahuan yang dimiliknya dengan penerapannya dalam kehidupan sehari-hari (Usman, 2015). Teknik Contextual Teaching and Learning adalah teknik penyajian materi pelajaran dengan cara guru menggunakan contoh-contoh benda yang ada di lingkungan sekitar.

Mengacu pada paparan di atas, penulis mencoba untuk memberi altgernatif pemecahan masalah, yaitu dengan menrapakan teknik Contexctual Teaching and Learning pada materi Menggambar Bentuk di kelas VIIB SMPN 2 Palimanan, diharapkan dengan menggunakan teknik tersebut mampu meningkatkan prestasi belajar siswa pada semester 1 oktober 2019.

\section{Metode Penelitian}

Metode penelitian yang dilakukan penulis adalah Penelitian Tindakan Kelas (PTK) yang mengacu kepada tindakan guru ketika melaksanakan pembelajaran sebagai upaya untuk memperbaiki kegiatan pembelajaran yang telah dilaksanakan. Hal ini sesuai dengan pernyataan Suharjono (Arikunto, 2006:58) yang mengemukakan bahwa "penelitian tindakan kelas adalah penelitian tindakan yang dilakukan di kelas dengan tujuan memperbaiki/meningkatkan mutu praktik belajar".

Desain PTK yang digunakan yaitu model siklus menurut Kemis dan Mc.Taggart (Suyanto, 1997 : 16) yaitu terdiri dari empat komponen yaitu : 


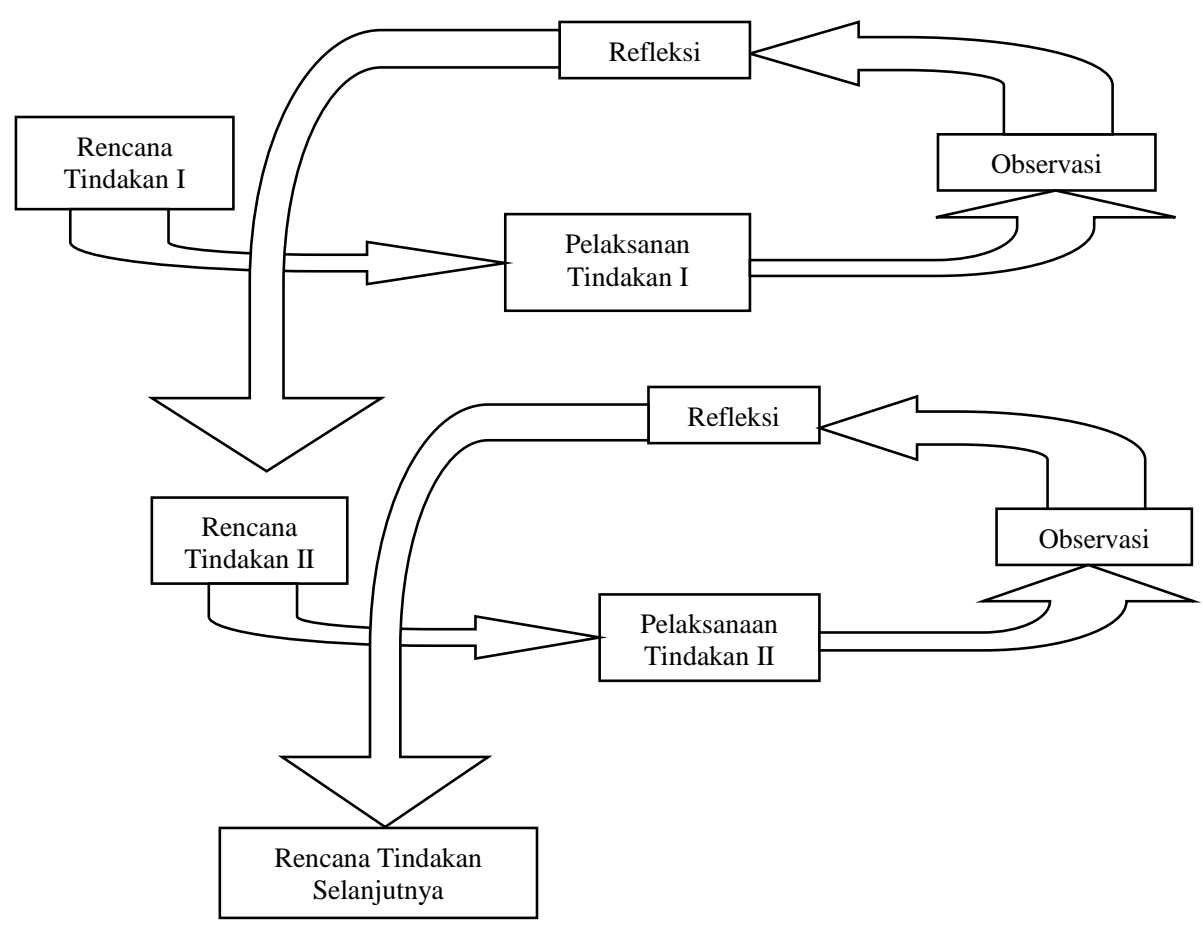

Gambar 1. Alur Penelitian Tindakan Kelas (Kasbolah, 1998 : 70).

Sumber data dalam penelitian ini adalah siswa kelas VIIB F SMP Negeri 2 Palimanan tahun pelajaran 2019/2020 sebanyak 36 orang, terutama dalam bentuk aktivitas siswa dan prestasi belajar siswa setelah mengikuti pembelajaran menggambar bentuk. Data yang ingin diperoleh peneliti adalah data aktivitas siswa dan nilai tes akhir setelah pembelajaran menggambar bentuk. Untuk memperoleh kedua data penelitian tersebut penulis menggunakan alat pengumpul data, yaitu (1) lembar pengamatan/observasi; dan (2) soal tes akhir pembelajaran menggambar bentuk. Untuk mengamati aktivitas siswa dan guru dalam melaksanakan pembelajaran menggambar bentuk, penulis dibantu oleh teman sejawat yaitu guru Seni Rupa dengan menggunakan lembar pengamatan yang telah disiapkan.

Penelitian tindakan kelas ini dianggap berhasil jika kemampuan para siswa dalam menggambar bentuk telah dianggap tuntas. Artinya, pembelajaran menggambar bentuk dalam mata pelajaran Seni Rupa dianggap berhasil jika rata-rata nilai tes akhir para siswa telah mencapai nilai standar kentutasan belajar minimal (KKM), yaitu 7,3 .

\section{Hasil dan Pembahasan}

Kegiatan pembelajaran seni rupa dalam materi "menggambar bentuk" di Kelas VIIB SMP Negeri 2 Palimanan dalam penelitian tindakan kelas ini dilaksanakan 2 siklus, setiap siklus terdiri dari 1). Studi pendahuluan, 2). Perencanaan, 3). Tindakan, 4). Observer dan 5). Refleksi kegiatan yang dilaksanakan. Pada awal pembelajaran guru memberikan motivasi yang menuntun siswa untuk mengingat kembali materi yang akan dibahas, memberikan motivasi kepada siswa agar ikut aktif berperan serta dalam proses belajar, serta menginformasikan tentang kompetensi yang harus dikuasai, menggunakan Contextual Teaching and Learning. 
Pada siklus I, awal pembelajaran observasi dilakukan terhadap guru membuka pelajaran seperti apersepsi terhadap materi yang akan dibahas dan memberikan motivasi kepada siswa. Pada siklus pertama observer kinerja guru untuk kegiatan pendahuluan dinilai rata-rata baik, namun untuk pemecahan masalah, mengelola informasi, implementasi hasil, buku pelajaran yang relevan masih kurang. Berdasarkan hasil observasi kemampuan guru dalam mengajar, sikap guru dalam pelajaran, penguasaan materi, proses pembelajaran, pemakaian media, kemampuan menutup pelajaran dinilai cukup (C) oleh observer.

Pada silus II, penulis mengadakan kolaborasi dengan guru lain dalam menyusun rencana penelitian, yang meliputi: 1) tujuan pembelajaran, 2) kompetensi dan materi pembelajaran, 3) strategi pembelajaran berupa metode dan media yang digunakan serta sumber belajar, dan 4) evaluasi hasil belajar. Langkah yang digunakan pada siklus ini adalah guru melakukan kegiatan pembelajaran sesuai deengan rencana pelaksanaan pembelajaran (RPP) yang meliputi kegiatan pendahuluan, kegiatan inti dan kegiatan penutup. Dari hasil observasi diperoleh kesimpulan kemampuan guru dalam pelajaran, sikap guru dalam pelajaran, penguasaan materi, proses pembelajaran, pemakaian media, kemampuan menutup pelajaran dinilai baik (B) oleh observer.

Adapun Berdasarkan hasil analisis data hasil penelitian diperoleh data motivasi belajar siswa mengenai (A) keterampilan bertanya, (B) respon menjawab pertanyaan, (C) keseriusan mempelajari materi, (D) partisipasi dalam kelompok, dan (E) kecepatan merespon tugas, diperoleh data temuan sebagai berikut.

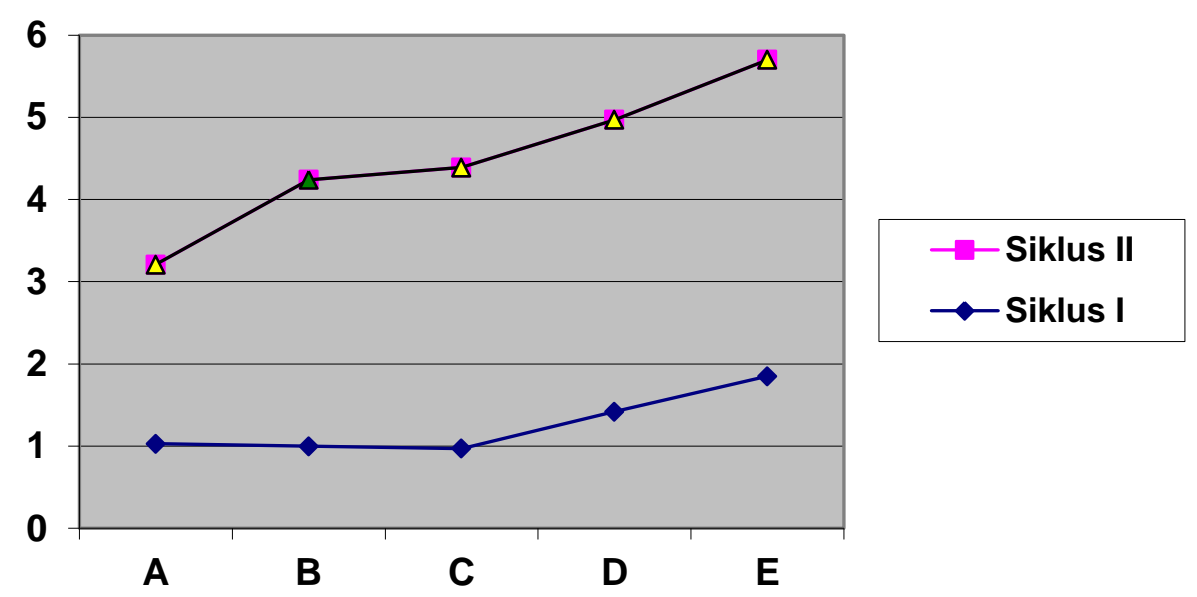

Gambar 2. Rekapitulasi Data Motivasi Belajar Siswa dari Dua Siklus

Berdasarkan diagram di atas jelaslah bahwa kenaikan motivasi belajar siswa yang paling besar terdapat dalam kcepatan siswa dalam merespon tugas. Hal ini berarti bahwa siswa termotivasi untuk dapat melaksanakan tugas dengan sebaik-baiknya. Selanjutnya diantara lima indikator tentang motivasi belajar siswa, kemampuan bertanya merupakan kemampuan yang perlu terus ditingkatkan.

Adapun data hasil tes kemampuan menggambar bentuk pada siklus kesatu dan kedua dapat dilihat dalam tabel berikut :

Tabel 1

Data Nilai Tes Akhir Pembelajaran Menggambar bentuk

\begin{tabular}{cccccc}
\hline \multirow{2}{*}{ No } & \multirow{2}{*}{ Nama Siswa } & \multicolumn{2}{c}{ Data Nilai } & \multirow{2}{*}{ Rata-Rata } & \multirow{2}{*}{ Kenaikan } \\
\hline 1 & 2 & 3 & 4 & 5 & 6 \\
\hline
\end{tabular}




\begin{tabular}{|c|c|c|c|c|c|}
\hline \multirow{2}{*}{ No } & \multirow{2}{*}{ Nama Siswa } & \multicolumn{2}{|c|}{ Data Nilai } & \multirow{2}{*}{ Rata-Rata } & \multirow{2}{*}{ Kenaikan } \\
\hline & & Siklus 1 & Siklus 2 & & \\
\hline 1 & Aldi B. & 6,0 & 7,0 & 6,5 & 1 \\
\hline 2 & Ali Topan & 7,0 & 8,0 & 7,5 & 1 \\
\hline 3 & Ani Fitriani & 5,0 & 6,0 & 5,5 & 1 \\
\hline 4 & Asep Mulyanto & 6,0 & 7,0 & 6,5 & 1 \\
\hline 5 & Churniawan S. & 7,0 & 7,0 & 7 & 0 \\
\hline 6 & Cucu Adiningsih & 6,5 & 8,0 & 7,25 & 1,5 \\
\hline 7 & Darinih & 7,0 & 8,0 & 7,5 & 1 \\
\hline 8 & Deri Oktavianus & 6,0 & 7,0 & 6,5 & 1 \\
\hline 9 & Diah Ayu Lusiana & 8,0 & 8,5 & 8,25 & 0,5 \\
\hline 10 & Dian Esti K. & 7,5 & 9,0 & 8,25 & 1,5 \\
\hline 11 & Dian Nuraini & 6,0 & 7,5 & 6,75 & 1,5 \\
\hline 12 & Dodi Irawan & 5,0 & 6,0 & 5,5 & 1 \\
\hline 13 & Gina Sonia & 7,0 & 7,0 & 7 & 0 \\
\hline 14 & Herawati & 7,5 & 7,5 & 7,5 & 0 \\
\hline 15 & Kadman & 6,0 & 8,5 & 7,25 & 2,5 \\
\hline 16 & Karmadi & 6,5 & 7,5 & 7 & 1 \\
\hline 17 & Katono & 6,0 & 8,0 & 7 & 2 \\
\hline 18 & Kunaenah & 5,0 & 7,0 & 6 & 2 \\
\hline 19 & Linda Komala & 6,0 & 8,0 & 7 & 2 \\
\hline 20 & Mulya & 7,0 & 8,0 & 7,5 & 1 \\
\hline 21 & Nengsih & 7,5 & 8,5 & 8 & 1 \\
\hline 22 & Neni Mulyani & 8,0 & 8,5 & 8,25 & 0,5 \\
\hline 23 & Novi Erlinih & 7,0 & 8,5 & 7,75 & 1,5 \\
\hline 24 & Nur Arunah & 6,0 & 8,0 & 7 & 2 \\
\hline 25 & Nur Rohman & 5,0 & 7,0 & 6 & 2 \\
\hline 26 & Oni Lyanti & 7,0 & 8,0 & 7,5 & 1 \\
\hline 27 & Ratini & 6,0 & 8,5 & 7,25 & 2,5 \\
\hline 28 & Reni Fajarwati & 6,0 & 7,5 & 6,75 & 1,5 \\
\hline 29 & Riki & 7,0 & 8,5 & 7,75 & 1,5 \\
\hline 30 & Rini Safitri & 5,0 & 7,0 & 6 & 2 \\
\hline 31 & Rismayanti & 7,0 & 8,5 & 7,75 & 1,5 \\
\hline 32 & Rudi & 7,5 & 8,5 & 8 & 1 \\
\hline 33 & Siti Anisah & 7,0 & 8,0 & 7,5 & 1 \\
\hline & Jumlah & 214 & 255,5 & 234,75 & 41,5 \\
\hline & Rata-rata & 6,48 & 7,74 & 7,11 & 1,26 \\
\hline
\end{tabular}

Berdasarkan tabel di atas diketahui bahwa rata-rata nilai siswa pada siklus pertama sebesar 6,48 apabila dibandingkan dengan KKM yang ditetapkan sebesar 7,3, pembelajaran tersebut belum berhasil, namun guru selaku peneliti sepakat dengan teman sejawat selaku observer yakin pada pertemuan selanjutnya, yaitu pembelajaran menggambar bentuk dengan menggunakan teknik teknik Contextual Teaching and Learning Tipe Pemodelan dapat akan meningkatkan motivasi belajar dan prestasi siswa.

Nilai tes akhir setelah pembelajaran pada siklus kedua, rata-rata nilai siswa sebesar 7,74 telah berhasil mencapai KKM yang ditetapkan yaitu sebesar 7,3. Dengan demikian, pembelajaran menggambar bentuk pada siswa kelas VIIB SMP Negeri 2 Palimanan tahun pelajaran 2019/2020 telah berhasil mencapai nilai KKM. Artinya, pembelajaran menggambar bentuk dengan menggunakan teknik Contextual Teaching and Learning efektif. 


\section{Kesimpulan}

Presatasi belajar siswa mata pelajaran Seni Budaya pada materi Membentuk Gambar. Tingginya motivasi belajar siswa tersebut berpengaruh pada pencapaian rata-rata nilai tes akhir, yaitu 7,74. Nilai tersebut telah melampaui nilai standar ketuntasan belajar minimal, yaitu 7,3. Dengan demikian, dapat dikatakan pembelajaran menggambar bentuk dengan menggunakan teknik Contextual Teaching and Learning tergolong efektif.

\section{Daftar Pustaka}

Amir, MF. (2015). Pengaruh Pembelajaran Kontekstual Terhadap Kemampuan Pemecahan Masalah Matematika Siswa Sekolah Dasar. Prosiding Seminar Nasional "Peningkatan Kualitas Peserta Didik Melalui implementasi Pembelajaran Abad 21", 34-42

Arikunto, S. (2006). Prosedur Penelitian Suatu Pendekatan Praktik. Jakarta: Rineka Cipta.

Djamarah, SB. (2008). Psikologi Belajar. Jakarta: Rineka Cipta.

Efniati, E. (2019). Penerapan Metode Pembelajaran Kontekstual Untuk Meningkatkan Hasil Belajar Seni Budaya Pada Siswa Kelas VII-3 SMP Negeri 14 Bandar Lampung Semester Ganjil Tahun Pelajaran 2014/2015. Lentera: Jurnal Ilmiah Kependidikan, 1, 129$146 . \quad$ Retrieved from http://jurnal.stkippgribl.ac.id/index.php/lentera/article/view/176

Hartono. (2007). Pengembangan Model Pembelajaran Seni Berbasis Kompetensi Pada Anak Usia Dini. Harmonia Jurnal Pengetahuan Dan Pemikiran Seni, 3(1), 1-12.

Jhonson. Elaine. (2007). Contextual Teaching and Learning. Menjadikan Belajar-Mengajar Mengasyikkan dan Bermakna. Diterjemahkan Ibnu Setiawan. Bandung. Mizan Media Utama.

Kasbolah, K. (1998). Penelitian Tindakan Kelas. Malang, Depdikbud

Nurhadi. (2002). Pendekatan Kontekstual (Contextual Teaching and Learning). Malang. Universitas Negeri Malang

Rofian. (2016). Penerapan Metode Pembelajaran Demostrasi Pada Pendidikan Seni Rupa Di Sekolah Dasar. Majalah Ilmiah Pendidikan Dasar, 6(2), 173-181

Sanjaya, W. (2010). Starategi Pembelajaran Berorientasi Standar Roses Pendidikan. Jakarta. Prenada Media Group.

Slameto. (1995). Belajar dan Faktor-Faktor yang Mempengarubinya. Jakarta: Rineka Cipta.

Suyanto.(1997) Pedoman pelaksaaa penelitian kelas. Jakarta: Dirjen Dikti.

Usman, R. (2015). Penerapan Metode Contextual Teaching And Learning Untuk Meningkatkan Hasil Belajar Membaca Kritis Paragraf Materi Transportasi Siswa Kelas V SD Negeri 035 Pekanbaru. Jurnal SOROT, 10(1), 1 - 142 